\title{
Effect of Annealing Process on the Properties of Ni(55\%)Cr(40\%)Si(5\%) Thin-Film Resistors
}

\author{
Huan-Yi Cheng ${ }^{1}$, Ying-Chung Chen ${ }^{1}$, Pei-Jou Li ${ }^{1}$, Cheng-Fu Yang ${ }^{2, *}$ and Hong-Hsin Huang ${ }^{3}$ \\ Received: 12 August 2015 ; Accepted: 22 September 2015 ; Published: 2 October 2015 \\ Academic Editor: Teen-Hang Meen \\ 1 Department of Electrical Engineering, National Sun Yat-sen University, Kaohsiung 804, Taiwan; \\ eveflora818@gmail.com (H.-Y.C.); ycc@mail.ee.nsysu.edu.tw (Y.-C.C.); sunnyrain516@hotmail.com (P.-J.L.) \\ 2 Department of Chemical and Materials Engineering, National University of Kaohsiung, \\ No. 700 Kaohsiung University Road, Nan-Tzu District, Kaohsiung 811, Taiwan \\ 3 Department of Electrical Engineering, Cheng Shiu University, Kaohsiung 833, Taiwan; \\ k0511@gcloud.csu.edu.tw \\ * Correspondence: cfyang@nuk.edu.tw; Tel.: +886-7-5919283; Fax: +886-7-5919277
}

\begin{abstract}
Resistors in integrated circuits (ICs) are implemented using diffused methods fabricated in the base and emitter regions of bipolar transistor or in source/drain regions of CMOS. Deposition of thin films on the wafer surface is another choice to fabricate the thin-film resistors in ICs' applications. In this study, $\mathrm{Ni}(55 \%) \mathrm{Cr}(40 \%) \mathrm{Si}(5 \%)$ (abbreviated as $\mathrm{NiCrSi}$ ) in wt \% was used as the target and the sputtering method was used to deposit the thin-film resistors on $\mathrm{Al}_{2} \mathrm{O}_{3}$ substrates. NiCrSi thin-film resistors with different thicknesses of $30.8 \mathrm{~nm} \sim 334.7 \mathrm{~nm}$ were obtained by controlling deposition time. After deposition, the thin-film resistors were annealed at $400{ }^{\circ} \mathrm{C}$ under different durations in $\mathrm{N}_{2}$ atmosphere using the rapid thermal annealing (RTA) process. The sheet resistance of $\mathrm{NiCrSi}$ thin-film resistors was measured using the four-point-probe method from $25^{\circ} \mathrm{C}$ to $125^{\circ} \mathrm{C}$, then the temperature coefficient of resistance could be obtained. We aim to show that resistivity of NiCrSi thin-film resistors decreased with increasing deposition time (thickness) and the annealing process had apparent effect on the sheet resistance and temperature coefficient of resistance. We also aim to show that the annealed $\mathrm{NiCrSi}$ thin-film resistors had a low temperature coefficient of resistance (TCR) between $0 \mathrm{ppm} /{ }^{\circ} \mathrm{C}$ and $+50 \mathrm{ppm} /{ }^{\circ} \mathrm{C}$.
\end{abstract}

Keywords: $\mathrm{Ni}(55 \%) \mathrm{Cr}(40 \%) \mathrm{Si}(5 \%)$; thin-film resistor; deposition time; rapid thermal annealing

\section{Introduction}

BiCMOS can provide superior performance for the applications in different circuits. Thus, the analog functions in BiCMOS require passive circuit components having small temperature coefficients, and the process sequence must be able to accommodate their fabrication. Resistors in integrated circuits (ICs) are implemented using diffused methods fabricated in the base and emitter regions of bipolar transistor or in source/drain regions of CMOS [1,2]. To deposit thin films on the wafer surface is another way to fabricate the passive resistors. Thin-film resistors are used extensively in electronic circuits due to their high accuracy and excellent long term stability. So far, there are various specific materials currently used as thin-film resistors in ICs' applications, such as $\mathrm{Cr}-\mathrm{Si}-\mathrm{Ta}-\mathrm{Al}$ [3], Ti-Si-V-N [4], and CuAlMo [5], respectively. One of the most widely used thin-film resistors is nickel-hromium $(\mathrm{NiCr})$ which has a low temperature coefficient of resistance (abbreviated as TCR) between $-50 \mathrm{ppm} /{ }^{\circ} \mathrm{C}$ and $+50 \mathrm{ppm} /{ }^{\circ} \mathrm{C}[6,7]$ and has a wide sheet resistance range of 10 to $500 \Omega$ /square [8]. Ni-Cr thin-film-based resistors are extensively used as discrete loads or potentiometers in hybrid circuits. Excellent wear and corrosion resistance makes $\mathrm{Ni}-\mathrm{Cr}$ thin films an attractive material for fusible links in programmable read only memories [6]. Recently, there 
has been an increase in demand for thin-film resistors with lower value of $0.1 \sim 10 \Omega$, especially in portable electronic devices for the purpose of saving battery power [9]. This requirement is difficult to meet with the properties of NiCr-based thin-film resistors, because as the thickness of NiCr-based thin-film resistors increases, the cost of deposition process increases and problems at the subsequent laser trimming stage will occur, because they become difficult to ablate.

There are different materials currently used as thin-film resistors in IC applications and $\mathrm{Cr}-\mathrm{Si}$ thin films are very interesting materials. The $\mathrm{Cr}-\mathrm{Si}$ thin films can be deposited as the thin-film-resistors because of existing certain advantages, including high sheet resistance, low TCR, high thermal stability, good long-term reliability, and chemical stability, respectively [10]. Dong et al. previous investigation proved that $\mathrm{Cr}-\mathrm{Si}(\mathrm{Cr}: \mathrm{Si}=1: 3)$ thin films doping with $3-6$ at $\% \mathrm{Ni}$ had the resistivity of 1.31-1.49 times higher than that of $\mathrm{Cr}-\mathrm{Si}$ thin films without $\mathrm{Ni}[11,12]$. They also found that the TCR of thin films could be adjusted to close zero by using annealing process. However, the resistivity of $\mathrm{Cr}-\mathrm{Si}-\mathrm{Ni}$ films was decreased when $\mathrm{Ni}$ content was higher than 6 at \%. The results suggested that a moderate $\mathrm{Ni}$ addition, for example, equal and higher than $40 \mathrm{wt} \%$ of $\mathrm{Ni}$ in $\mathrm{Cr}$ films [7] or equal and higher than 6 at \% of $\mathrm{Ni}$ in $\mathrm{Cr}-\mathrm{Si}$ films was favorable to the electrical stability [11]. In this study, $\mathrm{Ni}(55 \%) \mathrm{Cr}(40 \%) \mathrm{Si}(5 \%)$ (abbreviated as $\mathrm{NiCrSi}$ ) in wt \% was used as the target because the NiCrSi thin films had the merit of long-term stability [13] and the sputtering method was used to deposit the thin-film resistors on glass substrates. After deposition, the thin-film resistors were also annealed at $400{ }^{\circ} \mathrm{C}$ under different duration using the rapid thermal annealing (RTA) process. The sheet resistance of thin-film resistors was measured using the four-point-probe method. We would show that resistivity of NiCrSi thin-film resistors decreased with increasing deposition time and the annealing process had no apparent effect on the value of sheet resistance and the TCR.

\section{Experimental Section}

The structure of deposited NiCrSi-based thin-films using for the measurements of physical and electrical properties was shown in Figure 1. Figure 1a shows the side view of the structure. The green glass paste on $\mathrm{Al}_{2} \mathrm{O}_{3}$ ceramic shown in Figure $1 \mathrm{~b}$ was used to protect the substrate, and it could be removed during the $\mathrm{NiCrSi}$ thin-film resistors' annealing process and following ultrasonic clean in deionized water. The length between two electrodes (or called the length of thin-film resistors) was $4.0 \mathrm{~mm}$, the widths of thin-film resistors and electrodes were $2.8 \mathrm{~mm}$, and the length of electrodes was $1.2 \mathrm{~mm}$, respectively, as Figure $1 \mathrm{a}, \mathrm{b}$ show. Commercial composition material $\mathrm{Ni}(55 \%) \mathrm{Cr}(40 \%) \mathrm{Si}(5 \%)$ (abbreviated as $\mathrm{NiCrSi}$ ) in wt \% was used as the target and the sputtering method was used to deposit $\mathrm{NiCrSi}$ thin films on $\mathrm{Al}_{2} \mathrm{O}_{3}$ substrates. The deposition parameters were power of $150 \mathrm{~W}$ at $5 \mathrm{mTorr}$ and at room temperature $\left(25^{\circ} \mathrm{C}\right)$, and the deposition time was changed from $30 \mathrm{~min}$ to $150 \mathrm{~min}$, respectively. After deposition, the deposited $\mathrm{NiCrSi}$ thin films were annealed by using the rapid thermal annealing (RTA) at $400{ }^{\circ} \mathrm{C}$ in $\mathrm{N}_{2}$ under different durations of $30 \mathrm{~s} \sim 10 \mathrm{~min}$. After NiCrSi-based thin-films were annealed, the glaze layer was removed by using ultrasonic method in deionized water. The surface morphology of deposited NiCrSi thin-film resistors was shown in Figure 1c. The crystalline structures of deposited and annealed NiCrSi-based thin-films were determined by means of X-ray diffraction (XRD) (Cu-K $\alpha$, Bruker D8, Billerica, MA, USA). The thickness measurement of deposited and annealed $\mathrm{Ni}-\mathrm{Cr}$-Si-based thin-films was obtained by using $\alpha$-step (Kosaka ET 4000, Tokyo, Japan). 
(a)
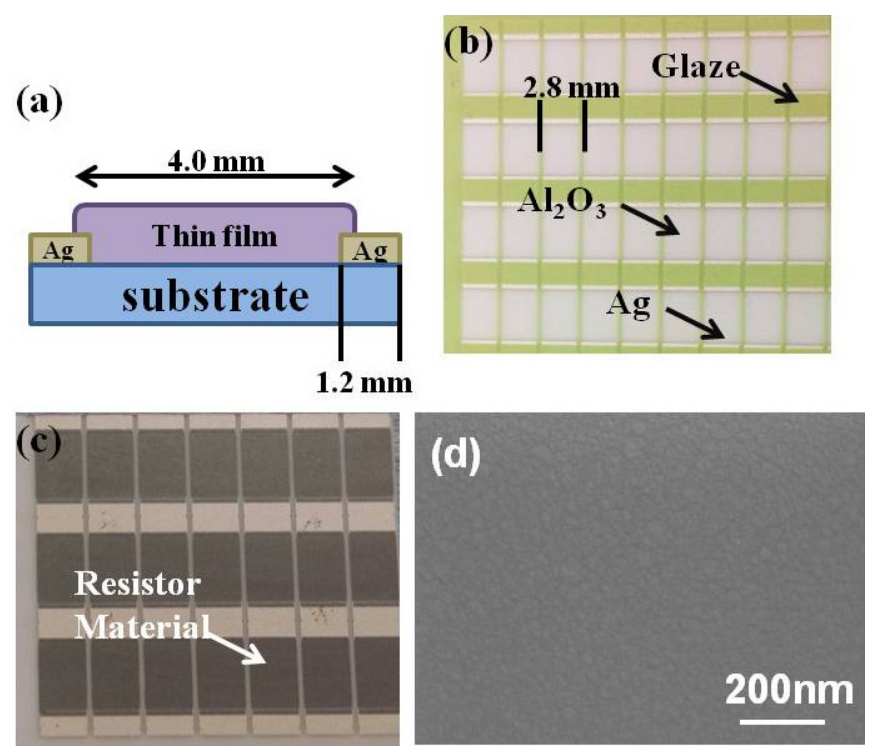

Figure 1. The structure of NiCrSi thin-film resistors (a) Side view; (b) top view before the protection glaze (green color) films were removed; and (c) top view, the protection glaze films were removed after the resistor material was deposited; (d) Surface morphology of deposited NiCrSi thin-film resistors.

The surface morphology of $\mathrm{NiCrSi}$ thin-film resistors was observed by field emission scanning electron microscopy (FESEM) (JEOL JSM-6700, Tokyo, Japan). As Figure 1d shows, only nano-crystalline grains were observed and surface morphology was almost unchanged as the different deposition time and the annealing process were used. The resistance was measured by using the four-point-probe method and the resistivity was calculated by the measured resistance and the thickness of Ni-Cr-Si-based thin films. Resistance values for materials at any temperature other than the standard temperature (usually specified at $20^{\circ} \mathrm{C}$ ) on the specific resistance table can be determined through the following formula:

$$
\mathrm{R}=\mathrm{R}_{\mathrm{ref}}\left[1+\alpha\left(\mathrm{T}-\mathrm{T}_{\mathrm{ref}}\right)\right]
$$

where $R$ is the material resistance at temperature $T, R_{\text {ref }}$ is the material resistance at temperature $T_{\text {ref }}$, usually $20^{\circ} \mathrm{C}$ or $0^{\circ} \mathrm{C}, \alpha$ is temperature coefficient of resistance (TCR) for the material symbolizing the resistance change factor per degree of temperature change, $\mathrm{T}$ is the material temperature in degrees Celcius, and $\mathrm{T}_{\text {ref }}$ is the reference temperature that $\alpha$ is specified at for the material, respectively. In this study, the measured temperatures were $25^{\circ} \mathrm{C}, 50{ }^{\circ} \mathrm{C}, 75^{\circ} \mathrm{C}, 100{ }^{\circ} \mathrm{C}$, and $125^{\circ} \mathrm{C}$, respectively, the resistivity measured at the two temperatures were used to find the temperature coefficient of resistance of $\mathrm{NiCrSi}$ thin-film resistors.

\section{Results and Discussion}

The effect of deposition time on the thickness of as-deposited and annealed $\mathrm{NiCrSi}$ thin films was investigated, and the results are shown in Figure 2. As the deposition temperature was $25{ }^{\circ} \mathrm{C}$, the thicknesses of the 15 min-, 30 min-, 60 min-, and 150 min-deposited NiCrSi thin films measured by using Ellipsometer and the thickness were around $30.8 \mathrm{~nm}, 90.7 \mathrm{~nm}, 140.1 \mathrm{~nm}$, and $334.7 \mathrm{~nm}$, respectively. As the deposition time increased, the increase in thickness of $\mathrm{NiCrSi}$ thin films is expectable. However, as $\mathrm{NiCrSi}$ thin films were annealed at $400{ }^{\circ} \mathrm{C}$ in $\mathrm{N}_{2}$ atmosphere, the thicknesses of the $15 \mathrm{~min}-, 30 \mathrm{~min}-, 60 \mathrm{~min}-$, and $150 \mathrm{~min}$-deposited NiCrSi thin films decreased slightly. 


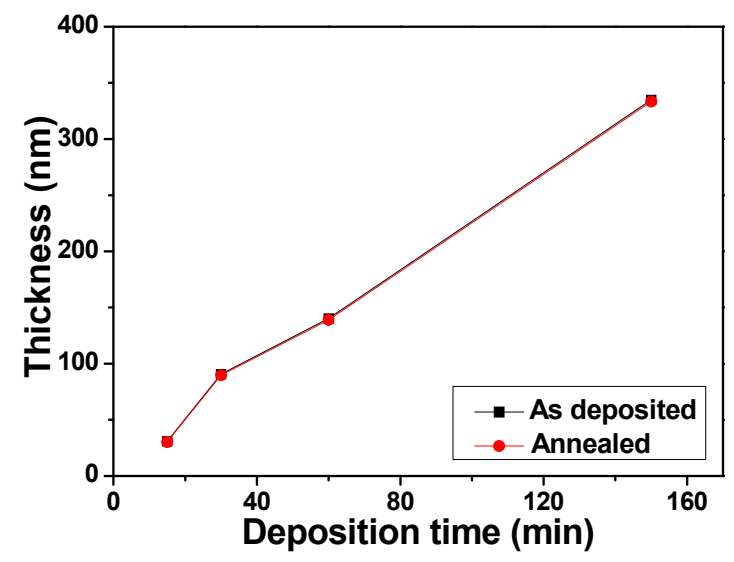

Figure 2. Thickness of as-deposited and annealed NiCrSi thin-film resistors.

XRD was used to investigate the structural properties of $\mathrm{NiCrSi}$ thin films deposition at room temperature in a pure Ar atmosphere. Figure 3 shows the XRD patterns of $\mathrm{Al}_{2} \mathrm{O}_{3}$ substrate, $\mathrm{Al}_{2} \mathrm{O}_{3}$ substrate with Ag paste. Figure 3 also shows the XRD patterns of the $15 \mathrm{~min}-, 30 \mathrm{~min}-, 60 \mathrm{~min}-$, and 150 min-deposited NiCrSi thin films with the different thicknesses. As Figure 3 shows, the XRD patterns of all deposited $\mathrm{NiCrSi}$ thin films revealed an amorphous structure and no apparent crystalline phases were observed. Only the $\mathrm{Ag}$ and $\mathrm{Al}_{2} \mathrm{O}_{3}$ phases were observed in Figure 3. Those results suggest that the thickness (or deposition time) will not affect the crystalline structure of deposited NiCrSi thin films.

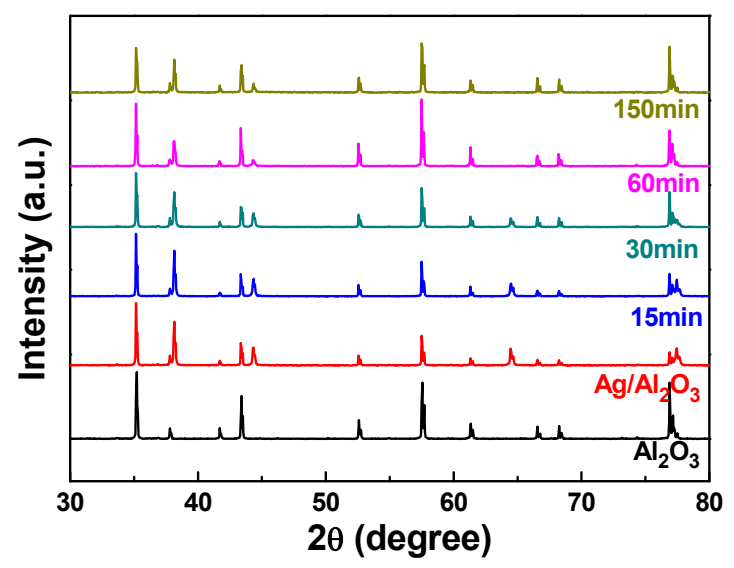

Figure 3. X-ray diffraction (XRD) patterns of deposited NiCrSi thin-film resistors.

Figure 4 shows the effect of thickness on the variations of resistance and resistivity for $\mathrm{NiCrSi}$ thin-film resistors measured at $25{ }^{\circ} \mathrm{C}$ and $125{ }^{\circ} \mathrm{C}$. The NiCrSi thin-film resistors' resistance was recorded by the four-point measurement and the resistivity was derived from the resistance using a measurement of film thickness. As Figure 4 shows, as the measured temperatures were increased from $25^{\circ} \mathrm{C}$ to $125^{\circ} \mathrm{C}$ (only measured at $25^{\circ} \mathrm{C}$ to $125^{\circ} \mathrm{C}$ were shown); however, the resistance of $\mathrm{NiCrSi}$ thin-film resistors increased slightly and they had similar results. Figure 4 also shows that the thinner $\mathrm{NiCrSi}$ thin-film resistors showed higher resistivity and the resistivity reached a saturation value as the thickness was equal and more than $140.1 \mathrm{~nm}$. If we suppose the thickness of $\mathrm{NiCrSi}$ thin-film resistors was independent of measured temperature, the resistivity of the $25^{\circ} \mathrm{C}$ - and $125^{\circ} \mathrm{C}$-measured $\mathrm{NiCrSi}$ thin-film resistors had almost the same values and the variations in resistivity were not apparently observed. Figure 4 shows that the resistivity linearly decreased with increasing $\mathrm{NiCrSi}$ thin-films' thickness. In the free-electron model of a metallic thin film with hard-wall boundary 
conditions, the discretization of energy levels makes it impossible to treat both the Fermi energy and the electron density as independent of the thickness [14].
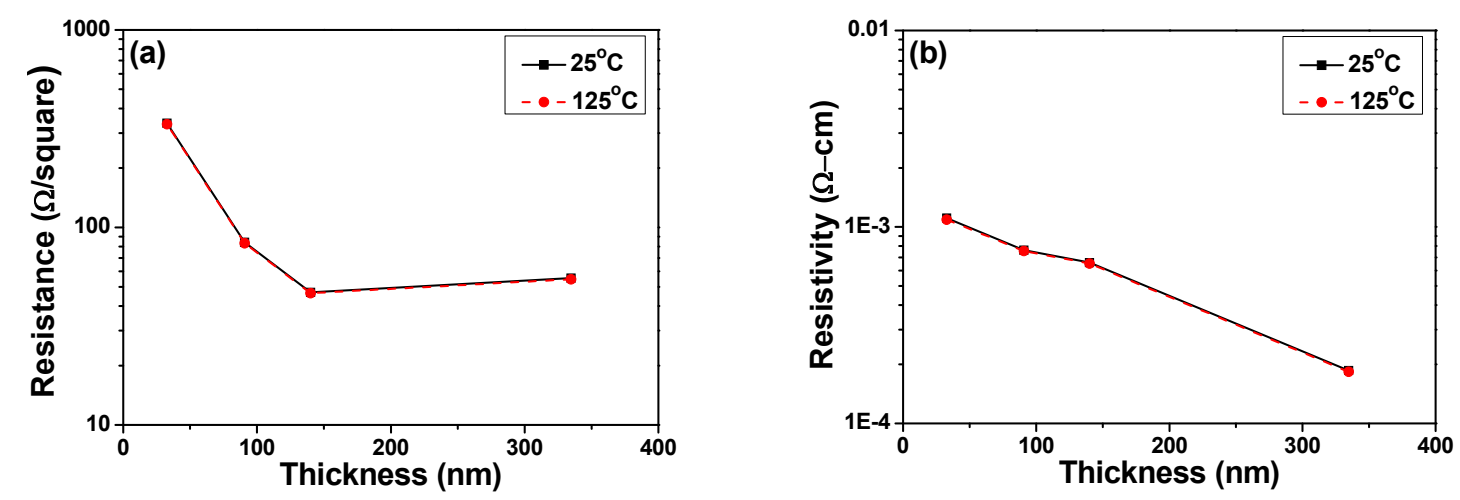

Figure 4. Effect of thickness on the variations of (a) resistance and (b) resistivity for NiCrSi thin-film resistors measured at $25^{\circ} \mathrm{C}$ and $125^{\circ} \mathrm{C}$.

Nevertheless, many scattering effects are believed to affect the resistivity of NiCrSi thin-film resistors, including surface scattering effect, grain boundaries scattering effect, uneven or rough surfaces scattering effect, and impurities scattering effect, respectively [15]. Surface scattering effect is dependent on the thickness of thin-film resistors and other effects are dependent on the procedures and conditions used to fabricate the thin films, and thus, it is very difficult to quantify each of these effects without measurement [15]. From the Lacy's propose, the electrical resistivity as a function of film thickness can be expressed as:

$$
\begin{gathered}
\rho=\frac{\rho_{\mathrm{o}}}{k[1-\ln k]} \\
\text { and } k=\frac{t / 2}{l}
\end{gathered}
$$

where $k$ is constant and $0<k \leqslant 1, \rho$ is resistivity of thin film resistors, $\rho_{\mathrm{o}}$ is the bulk resistivity of the material, $l$ is the average traveling distance of electrons an, $t$ is the thickness of thin film conductors and it is assumed to have smooth or even surfaces.

The TCR values of deposited NiCrSi thin-film resistors are shown in Figure 5 as a function of film's thickness, using the measured results shown in Figure 4. All of the TCR values of deposited $\mathrm{NiCrSi}$ thin-film resistors has a negative number, meaning that resistance decreases with increasing measured temperature. For pure metals, this coefficient is a positive number, meaning that resistance increases with increasing measured temperature. The TCR value of Ni metal is 0.00017 and the TCR value of $\mathrm{Cr}$ metal is $13 \times 10^{-8}$, respectively. Dhere et al. found that $\mathrm{Ni}-\mathrm{Cr}$ thin films of low positive TCR value (less than $100 \mathrm{ppm} /{ }^{\circ} \mathrm{C}$ ) were obtained at all thicknesses studied when the sum of the total atomic contents of chromium, oxygen and carbon reached 50\%-55\% [16]. For the elements silicon in single crystalline type, the TCR value is a negative number of about -0.04 (depending strongly on the presence of impurities in the material). Because of this, we believe the negative TCR value of $\mathrm{NiCrSi}$ thin-film resistors is caused by the addition of $\mathrm{Si}$ in $\mathrm{Ni}-\mathrm{Cr}$ alloy, and $\mathrm{Si}$ can be added in the $\mathrm{NiCr}$ composition for shifting the TCR values to close $0 \mathrm{ppm} /{ }^{\circ} \mathrm{C}$. The TCR shown in Figure 5 first shifted to small negative value as the thin films' thickness increased from $30.8 \mathrm{~nm}$ to $140.1 \mathrm{~nm}$ and then shifted to large negative value as the thin films' thickness increased to $334.7 \mathrm{~nm}$. The reason for this result is not really known, the formations of unknown alloy or compound during the annealing process is the possible reason for this result. 


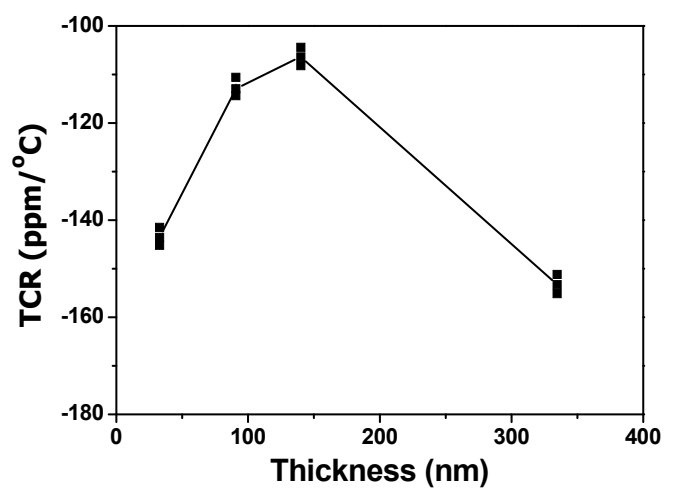

Figure 5. Effect of thickness on the variations of temperature coefficient of resistance (TCR) for the deposited $\mathrm{NiCrSi}$ thin-film resistors.

Lacy's proposal shows that as the thickness of thin-film resistors is thinner than $20 \mathrm{~nm}$, the resistivity of thin-film resistors will exponentially decrease. As the thickness of thin-film resistors is thicker than $20 \mathrm{~nm}$, the resistivity of thin-film resistors will linearly decrease. In a thin film material, if, as proposed, the thin films have smooth or even surfaces, the surface scattering (rather than other scatterings) is believed to be the main reason that will affect the resistivity of thin-film materials. In this study, the thickness of deposited thin films is thicker than $30 \mathrm{~nm}$. We believe the thin films are thick enough and the bulk mean free path of the electrons in $\mathrm{NiCrSi}$ thin-film resistors is less than $t / 2$. Therefore, only the partial electrons located at in the $t / 2$ region of upper face and down face will be scattered by the thin films' surfaces, and only partial electrons located at $t / 2$ the mean free path of the average conduction electrons will be altered or the electrons will be scattered by the surface. The ratio of conduction electrons will be altered or be scattered decreased with increasing the thickness of $\mathrm{NiCrSi}$ thin films. We believe this is the reason that the resistivity of $\mathrm{NiCrSi}$ thin-film resistors linearly decreases with increasing thickness.

Figure 6 shows the XRD patterns of 60 min-deposited $\mathrm{NiCrSi}$ thin films as a function of annealing time. As Figure 6 shows, only the $\mathrm{Ag}$ and $\mathrm{Al}_{2} \mathrm{O}_{3}$ phases were observed and no other crystalline phases were observed. Because the NiCrSi thin films are annealed in $\mathrm{N}_{2}$ atmosphere, we believe that the oxidation will not happen during the annealing process. Those results suggest the annealing process has no effect on the crystallization of $\mathrm{NiCrSi}$ thin films but it will have the chance to densify the NiCrSi thin films.

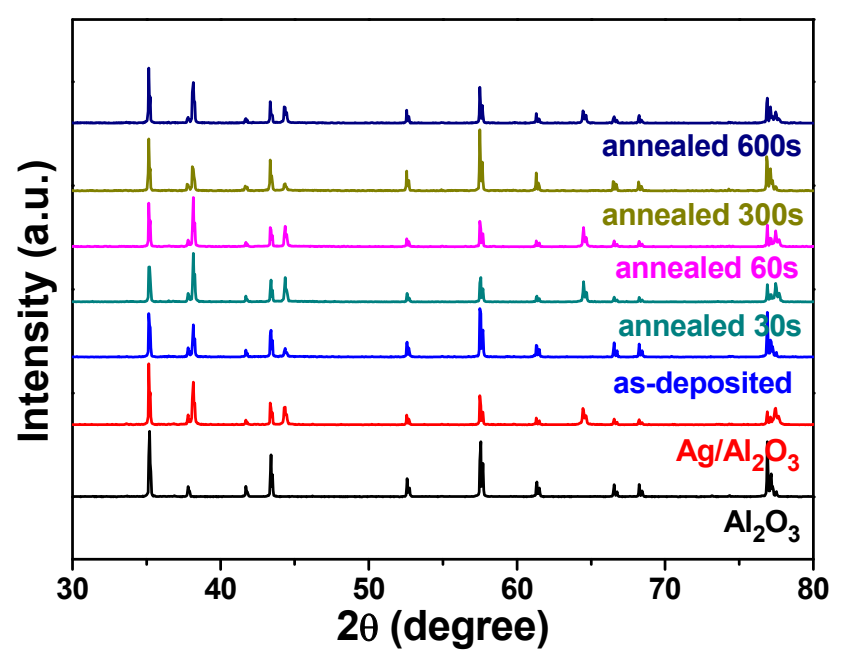

Figure 6. XRD patterns of annealed NiCrSi thin-film resistors, the deposition time was 60 min. 
The variations of resistance and resistivity of $\mathrm{NiCrSi}$ thin-film resistors after annealing process are shown in Figure 7 for the deposited thin films measured at $25^{\circ} \mathrm{C}$ and in Figure 8 for deposited thin films measured at $125^{\circ} \mathrm{C}$, respectively. Figures 7 and 8 show that as the thickness of NiCrSi thin-film resistors was equal and more than $91 \mathrm{~nm}$ and as the annealing time was equal and more than $60 \mathrm{~s}$, the resistance and resistivity would reach a stable value, independent of deposition time. Nocerinot and Singer find that the variations of resistance values were caused by two effects [17]. The first effect was adsorption of residual $\mathrm{O}_{2}$ gas during the deposition process. Because we deposited the thin films in the pure argon atmosphere, the effect of residual $\mathrm{O}_{2}$ gas on the properties of NiCrSi thin films can be neglected. The second effect was annealing of thin films, which would change the crystalline structure of thin-film materials or form chemical compound with thin-film materials. Thus, we anneal the NiCrSi thin films in the pure $\mathrm{N}_{2}$ atmosphere, the effect of chemical compound formed can also be neglected. However, the annealing process can stabilize the crystalline structure of deposition on thin films, because the resistivity and resistance of $\mathrm{NiCrSi}$ thin-film resistors will have a stable property after a period of annealing process.
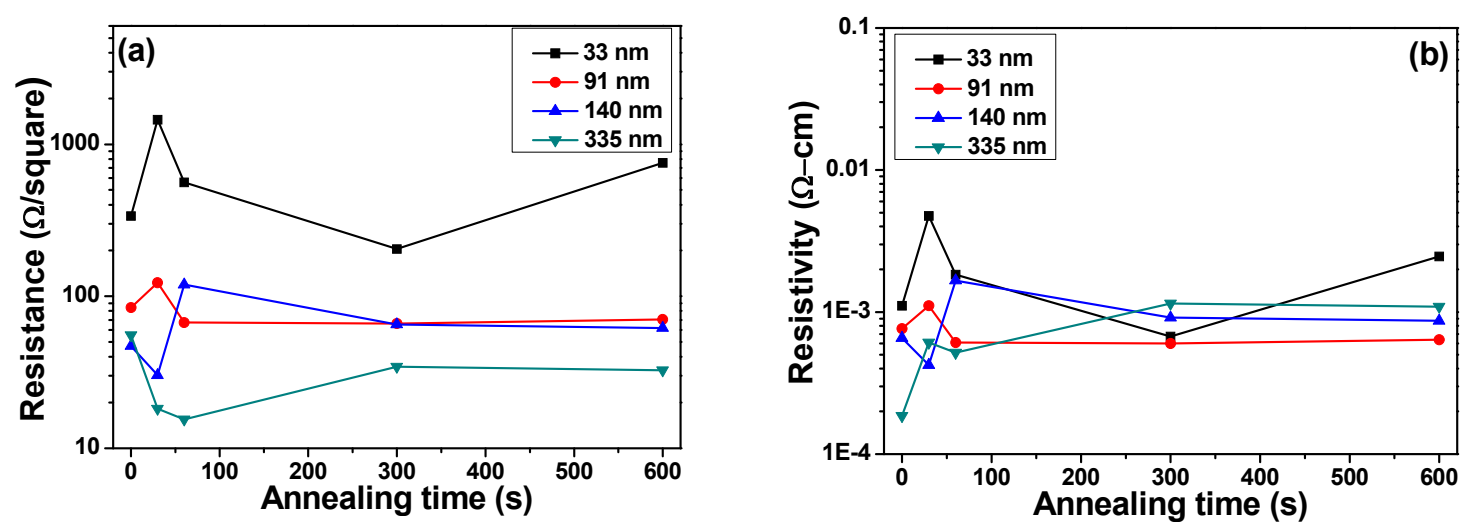

Figure 7. Variations of (a) resistance and (b) resistivity of $25^{\circ} \mathrm{C}$-measured NiCrSi thin-film resistors as a function of annealing time, respectively.
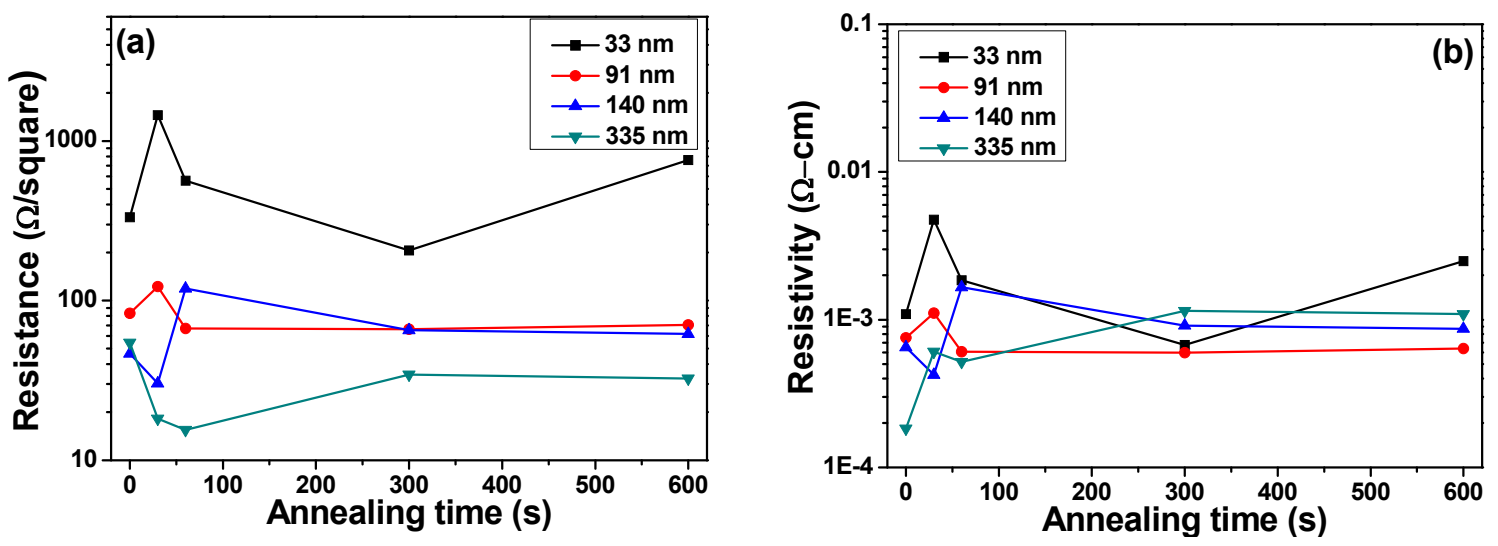

Figure 8. Variations of (a) resistance and (b) resistivity of $125^{\circ} \mathrm{C}$-measured $\mathrm{NiCrSi}$ thin-film resistors as a function of annealing time, respectively.

For applications of thin-film resistors, the temperature coefficient of resistance is hoped to be very close to zero, meaning that the resistance hardly changes at all with variations in temperature. In the past, the TCR values could be kept near zero for a wide variety of hybrid substrate materials with varied surface finishes by changing dopant concentration in the sputtering target. During the deposition process, the resistance and TCR value of thin-film resistors are also found to vary with 
both deposition and annealing parameters. Variations of TCR values of deposited NiCrSi thin-film resistors are shown in Figure 9 as a function of annealing time. Figure 9 shows that, as the annealing time was increased from $0 \mathrm{~s}$ to $60 \mathrm{~s}$, the TCR value of the $33 \mathrm{~nm}-\mathrm{NiCrSi}$ thin-film resistors changed from negative to positive; as the annealing time was increased from $60 \mathrm{~s}$ to $600 \mathrm{~s}$, the TCR value changed from $+31.7 \mathrm{ppm} /{ }^{\circ} \mathrm{C}$ to $94.2 \mathrm{ppm} /{ }^{\circ} \mathrm{C}$. As the thicknesses of $\mathrm{NiCrSi}$ thin-film resistors were $91 \mathrm{~nm}, 140 \mathrm{~nm}$, and $330 \mathrm{~nm}$ and as the annealing time was increased from $0 \mathrm{~s}$ to $60 \mathrm{~s}$, the TCR values changed from $-106.4 \sim-153.3 \mathrm{ppm} /{ }^{\circ} \mathrm{C}$ to $-41.9 \sim 0 \mathrm{ppm} /{ }^{\circ} \mathrm{C}$; as the annealing time was increased from $60 \mathrm{~s}$ to $600 \mathrm{~s}$, the TCR values were stable in the range of $-14.5 \mathrm{ppm} /{ }^{\circ} \mathrm{C}$ to $-37.7 \mathrm{ppm} /{ }^{\circ} \mathrm{C}$. Nocerinot and Singer found that the effects of introducing oxygen into the $\mathrm{Ni}-\mathrm{Cr}$ thin films during deposition process would decrease the TCR value [17]. However, we deposited and annealed the $\mathrm{NiCrSi}$ thin-film resistors in $\mathrm{Ar}$ and $\mathrm{N}_{2}$ atmosphere, respectively, the substrate used in this study is the high resistivity $\mathrm{Al}_{2} \mathrm{O}_{3}$, which has the resistivity higher than $10^{8} \Omega-\mathrm{cm}$. Therefore, the effect of substrates will be neglected. Bayne found that the TCR value of standard $60 / 40 \mathrm{Ni}-\mathrm{Cr}$ thin-film resistors was around $\sim 100 \mathrm{ppm} /{ }^{\circ} \mathrm{C}$ for constant sheet resistance films [18]. Those results suggest that before the annealing process the $\mathrm{Si}$ will dominate the characteristic of TCR, and after annealing process the effect of $\mathrm{Ni}-\mathrm{Cr} \mathrm{Si}$ will affect the characteristic of TCR, because the TCR value of $\mathrm{NiCrSi}$ thin-film resistors changes from negative to positive or shifts to near $0 \mathrm{ppm} /{ }^{\circ} \mathrm{C}$.

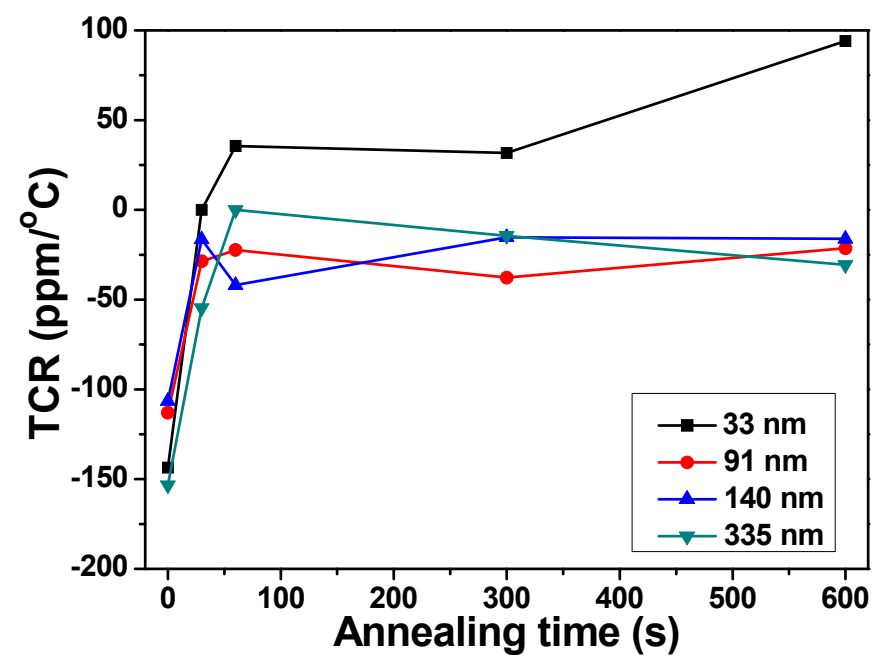

Figure 9. Variations of temperature coefficient of resistance of deposited $\mathrm{NiCrSi}$ thin-film resistors as a function of annealing time.

\section{Conclusions}

As the deposition time was $15 \mathrm{~min}, 30 \mathrm{~min}, 60 \mathrm{~min}$, and $150 \mathrm{~min}$, the thickness of NiCrSi thin films was around $30.8 \mathrm{~nm}, 90.7 \mathrm{~nm}, 140.1 \mathrm{~nm}$, and $334.7 \mathrm{~nm}$, respectively. All of the NiCrSi thin films showed amorphous phase even the deposition time was $150 \mathrm{~min}$, and even thin films annealed at $400{ }^{\circ} \mathrm{C}$ for $300 \mathrm{~s} \mathrm{NiCrSi}$ also showed amorphous phase. The resistivity of deposited NiCrSi thin-film resistors first increased with thickness and reached a saturation value as the thickness was equal and more than $140.1 \mathrm{~nm}$, and the resistivity linearly decreased with increasing NiCrSi thin-films' thickness. When the annealing process was used, as the thickness of $\mathrm{NiCrSi}$ thin-film resistors was equal and more than $91 \mathrm{~nm}$ and as the annealing time was equal and more than $60 \mathrm{~s}$, the resistance and resistivity would reach a stable value, independent of deposition time. As the thicknesses of $\mathrm{NiCrSi}$ thin-film resistors were $91 \mathrm{~nm}, 140 \mathrm{~nm}$, and $330 \mathrm{~nm}$, and the annealing time was more than $60 \mathrm{~s}$, the TCR values were stable in the range of $-14.5 \mathrm{ppm} /{ }^{\circ} \mathrm{C}$ to $-37.7 \mathrm{ppm} /{ }^{\circ} \mathrm{C}$.

Acknowledgments: The authors acknowledge financial supports of MOST 103-2221-E-390-026. 
Author Contributions: Cheng and Li helped proceeding the experimental processes, measurements, and data analysis; Chen and Yang organized the paper and encouraged in paper writing; Huang helped proceeding the experimental processes and measurements.

Conflicts of Interest: The authors declare no conflict of interest.

\section{References}

1. Mirouh, K.; Bouabellou, A.; Halimi, R.; Mosser, A.; Ehret, G. Microstructural study of annealed Cr/Si system using cross-sectional TEM combined with nano-analysis. Mater. Sci. Eng. B 2003, 102, 80-84. [CrossRef]

2. Labbani, R.; Halimi, R.; Bouabellou, A.; Bouguerra, A. Elaboration of thin chromium silicide layers on $\mathrm{P}^{+}$ implanted silicon. Nucl. Instrum. Methods Phys. Res. A 2002, 480, 223-228. [CrossRef]

3. Wang, X.Y.; Zhang, Z.S.; Bai, T. Investigation on powder metallurgy Cr-Si-Ta-Al alloy target for high-resistance thin film resistors with low temperature coefficient of resistance. Mater. Des. 2010, 31, 1302-1307. [CrossRef]

4. Fernandes, F.; Loureiro, A.; Polcar, T.; Cavaleiro, A. The effect of increasing V content on the structure, mechanicalproperties and oxidation resistance of $\mathrm{Ti}-\mathrm{Si}-\mathrm{V}-\mathrm{N}$ films deposited by $\mathrm{DC}$ reactive magnetron sputtering. Appl. Sur. Sci. 2014, 289, 114-123. [CrossRef]

5. Birkett, M.; Penlington, R.; Wan, C.; Zoppi, G. Structural and electrical properties of CuAlMo thin films prepared by magnetron sputtering. Thin Solid Films 2013, 540, 235-241. [CrossRef]

6. Vinayak, S.; Vyas, H.P.; Muraleedharan, K.; Vankar, V.D. Ni-Cr thin film resistor fabrication for GaAs monolithic microwave integrated circuits. Thin Solid Films 2006, 514, 52-57. [CrossRef]

7. Vinayak, S.; Vyas, H.P.; Vankar, V.D. Microstructure and electrical characteristics of Ni-Cr thin films. Thin Solid Films 2007, 515, 7109-7116. [CrossRef]

8. Van den Broek, J.J.; Donkers, J.J.T.M.; van der Rijt, R.A.F.; Janssen, J.T.M. Metal film precision resistors: Resistive metal films and a new resistor concept. Philips J. Res. 1998, 51, 429-447. [CrossRef]

9. Kang, B.; Hur, S.; Kim, D.; Yoon, S. Thickness Dependence of the Electrical Properties of CuNi Thin Film Resistors Grown on AlN Substrates for П -Type Attenuator Application. Electrochem. Solid State Lett. 2005, 8, G92-G94. [CrossRef]

10. Bruckner, W.; Grießmann, H.; Schreiber, H.; Vinzelberg, H.; Heinrich, A. Degradation of CrSi(W)-O resistive films. Thin Solid Films 1992, 214, 84-91. [CrossRef]

11. Zhang, Y.; Dong, X.; Wu, J.S. Microstructure and electrical characteristics of Cr-Si-Ni films deposited on glass and Si (100) substrates by RF magnetron sputtering. Mater. Sci. Eng. B 2004, 113, 154-160. [CrossRef]

12. Dong, X.P. The Study of Microstructure and Electrical Properties of Cr-Si Silicide Films; Shanghai Jiao Tong University: Shanghai, China, 2003.

13. Gawalek, W. Resistance, temperature coefficient of resistance and long-term stability of annealed thin Ni-Cr-Si films. Thin Solid Films 1984, 116, 205-210. [CrossRef]

14. Wang, Z.; Wang, S.; Shen, S.; Zhou, S. Impurity resistivity of an ideal metallic thin film. Phys. Rev. B 1997, 55, 10863-10868. [CrossRef]

15. Lacy, F. Developing a theoretical relationship between electrical resistivity, temperature, and film thickness for conductors. Nanoscale Res. Lett. 2011, 6, 636. [CrossRef] [PubMed]

16. Dhere, N.G.; Vaiude, D.G.; Wolfgang Losch, W. Composition and temperature coefficient of resistance of $\mathrm{Ni}-\mathrm{Cr}$ thin films. Thin Solid Films 1979, 59, 33-41. [CrossRef]

17. Nocerinot, G.; Singer, K.E. The Electrical and Compositional Structure of Thin Ni-Cr Films. Thin Solid Films 1979, 57, 343-348. [CrossRef]

18. Bayne, M.A. Al-doped Ni-Cr for temperature coefficient of resistance control in hybrid thin-film resistors. J. Vac. Sci. Technol. A Vac. Surf. Films 1986, 4, 3142-3145. [CrossRef]

(C) 2015 by the authors; licensee MDPI, Basel, Switzerland. This article is an open access article distributed under the terms and conditions of the Creative Commons by Attribution (CC-BY) license (http://creativecommons.org/licenses/by/4.0/). 